periphery of oasis, and in uneven sands, on sandy ridges and on the takyr plains of the clay desert quantity her not high (5-6\% hits, or on the average on 1 ha $3-4$ youngs of wild animal).

\title{
DIAGNOSTIC VALUE OF THE DETERMINATION OF THE LEVEL OF CONDUCTIVE CYTOKINES IN CERVICAL INTRAEPITELIAL NEOPLASIA
}

\section{SUMMARY}

Kalandarova Amina Nurullaevna

Candidate of medicine science,

Aripova Tamara Uktamovna

Academician, Doctor of medicine science Institute of Human Immunology and

Genomics Academy of Sciences of the Republic of Uzbekistan

The results of a comprehensive survey of 111 women of reproductive age with varying degrees of CIN residing in the Republic of Karakalpakstan were studied. The following research methods were used: clinical, ultrasound, endoscopic (colposcopy), cytological, immunological, bacterioscopic, bacteriological, PCR. It was revealed that the severity of immunological disorders is correlated with the nature of pathological changes in cervical intraepithelial tissue, which indicates the involvement of the immune system in the pathogenesis of CIN.

Key words: cervical intraepithelial neoplasia, immunity, immunocorrection.

By diseases of the cervix, prior invasive cervical cancer or precancerous cervical disease include epithelial dysplasia I-III severity [cervical intraepithelial neoplasia (Cervical Intraepithelial Neoplasia - CIN) or squamous intraepithelial lesions (Squamous Intraepithelial Lesion - SIL)]. Cervical intraepithelial neoplasias are characterized by impaired differentiation of epithelial cells as a result of proliferation of cambial elements with the development of their atypia, loss of polarity and impaired histostructure [6,7].

It is promising to study the characteristics of local production of cytokines in PVI associated with neoplastic changes in the cervical epithelium, which is necessary to assess the immune response and predict the risk of malignant transformation of infected cells $[2,4]$. The development of an immune response to a tumor antigen is not always a guarantee of the mobilization of antitumor protection, since it can lead to the induction of those immunological mechanisms that stimulate tumor growth. Despite the active study of the role of cytokines in the implementation of antitumor immunity, as well as their applicability in the diagnosis and treatment of tumors of different localization, the characteristics of cytokine metabolism and the dynamics of production of growth factors in patients with dysplasia and neoplasia of the cervical epithelium at the cervical level are not well understood.

Material and research methods

We presented data from our research on a comprehensive survey of 111 women of reproductive age with varying degrees of CIN living in the Republic of Karakalpakstan. Of the women surveyed, CIN I was detected in 45 , who made up the 1 st group, CIN II - in 35 women - the 2nd group and 31 women with CIN III - the 3rd group.

Immunological studies were conducted by studying some parameters of the cellular (CD3, CD4, CD8, CD16, CD20, CD25, CD95) humoral (IgG, IgA, IgM) and cytokine (IL-1b, IL-6, TNF $\alpha$ and IFN $\gamma$ ) status. The control group consisted of 24 healthy women.
We used the following research methods: clinical, ultrasound, endoscopic (colposcopy), cytological, immunological, bacterioscopic, bacteriological, PCR. Molecular biological studies with DNA typing and PCR were considered important and informative evidence of the presence of infectious pathogens. For the purpose of early diagnosis of cervical dysplasia, a study of smears from the surface of the cervical epithelium and cervical canal was performed.

Immunological research methods. Evaluation of the immune status of modern concepts implies a comprehensive study of the immune system, including testing its most important functional units. The determination of cellular immunity. Evaluation of the state of the immune system is carried out by expression of $\mathrm{CD}$ differentiation antigens. We identified the following markers of immunocompetent cells (ICC): $\mathrm{CD} 3+-, \mathrm{CD} 4+-, \mathrm{CD} 8+-, \mathrm{CD} 20+-, \mathrm{CD} 16+-$ lymphocytes. Determination of humoral immunity. The determination of the serum concentration of immunoglobulins of the main three classes A, M and G is carried out by the generally accepted method of radial immunodiffusion according to Mancini (1963).

Determination of cytokine status. The concentrations of cytokines IL-2, IL-6, TNF $\alpha$ and IFN $\gamma$ were determined in serum by the method of solid phase ELISA in accordance with the manufacturer's recommendations (Vector Best, Novosibirsk, Russian Federation).

\section{Results and discussion}

Analysis of the data showed that HPV was detected in $77.8 \%$ of the women surveyed. Of these, HPV risk of high oncogenic risk $(16,18,31,33)$ was detected in $28.6 \%$ of patients with CIN I, in $86.2 \%$ of patients with CIN II, in 88.6-88\% of patients with CIN III and cervical cancer. Analysis of the data for the presence of TORCH infection showed a fairly high detectability of HSV (85.9\%) and CMV (87.8\%) infections, urea- (25.6\%) - and mycoplasma (14.7\%), Chlamydia trachomatis $(42,3 \%)$, Mycoplasma genitalium (42.3\%). Mixed infection was observed in $36.8 \%$ of the women surveyed. This suggests a certain 
synergism of interaction between viruses and ureamycoplasmas.

It is known that patients with certain congenital defects have a risk of developing malignant tumors 1000 times greater than the average in the population $[12,18,25]$.We have studied the heredity of the presence of cancer in history. It was found that in $13.1 \%$ of women with HPV and in $14.9 \%$ - without HPV, heredity was aggravated by various oncological diseases $(\mathrm{P}>0.05)$. Of these, 52\% indicated malignant diseases of the genitalia through the mother. The most frequently noted cervical and breast cancers, which accounted for $9.6 \%$ and $5.8 \%$, respectively. As a result of the obtained data, we can conclude that there is a high correlative dependence of the frequency of the pathology of the reproductive and somatic status of women $(r=0.54)$. The analysis made it possible to identify a group of factors that can be defined as predisposing and provoking. Predisposing factors lead to the formation of immunodeficiency states and the suppression of local defense mechanisms, and provocative factors trigger an infectious process against the background of an existing predisposition.

Immunological characteristics of women with CIN. Women with a reduced immune response are more susceptible to persistent infection with oncogenic human papilloma viruses and at risk of developing CIN and cervical cancer $[1,2]$. We have conducted studies on the state of the immune system of women with cervical intraepithelial neoplasia of various degrees. The women examined by us were 3 groups: the 1 st group - 45 women with CIN I, the 2nd group - 35 patients with CIN II and the 3rd group - 31 women with CIN III. Table 1 presents the data of cellular and humoral immunity. As can be seen from the presented data, the level of T-lymphocytes in patients is reduced, with the minimum value registered in women of the $3 \mathrm{rd}$ group $(\mathrm{P}<0.01)$.

\begin{tabular}{|c|c|c|c|c|}
\hline \multicolumn{1}{|c|}{ Table 1} \\
\hline Indicator & $\begin{array}{c}\text { Control } \\
\mathrm{n}=24\end{array}$ & $\begin{array}{c}\text { CIN I } \\
\mathrm{n}=45\end{array}$ & $\begin{array}{c}\text { CIN II } \\
\mathrm{n}=35\end{array}$ & $\begin{array}{c}\text { CIN III } \\
\mathrm{n}=31\end{array}$ \\
\hline $\mathrm{CD} 3+, \%$ & $53,8 \pm 1,7$ & $48,7 \pm 1,6^{*}$ & $45,4 \pm 1,7^{*}$ & $43,5 \pm 1,6^{*}$ \\
\hline $\mathrm{CD} 4+, \%$ & $31,2 \pm 1,3$ & $29,3 \pm 1,2^{*}$ & $27,6 \pm 1,3^{*}$ & $26,7 \pm 1,5^{*}$ \\
\hline $\mathrm{CD} 8+, \%$ & $23,6 \pm 1,1$ & $25,5 \pm 1,3$ & $28,3 \pm 1,4^{*}$ & $35,2 \pm 1,3^{*}$ \\
\hline $\mathrm{CD} 4 / \mathrm{CD} 8$ & $1,32 \pm 0,01$ & $1,14 \pm 0,02^{*}$ & $0,97 \pm 0,01^{*}$ & $0,75 \pm 0,01^{*}$ \\
\hline $\mathrm{CD} 16+\%$ & $13,7 \pm 0,9$ & $18,7 \pm 0,9^{*}$ & $13,7 \pm 0,9^{*}$ & $13,7 \pm 0,9^{*}$ \\
\hline $\mathrm{CD} 20+\%$ & $24,6 \pm 1,1$ & $28,6 \pm 1,2$ & $20,6 \pm 1,1^{*}$ & $18,6 \pm 0,9^{*}$ \\
\hline $\mathrm{CD} 25+\%$ & $23,5 \pm 1,2$ & $29,5 \pm 1,3^{*}$ & $31,4 \pm 1,4^{*}$ & $35,5 \pm 1,3^{*}$ \\
\hline CD95+, $\%$ & $28,7 \pm 1,4$ & $35,7 \pm 1,5^{*}$ & $22,9 \pm 1,3^{*}$ & $21,7 \pm 1,5^{*}$ \\
\hline
\end{tabular}

Note: * Values are reliable with respect to control data. groups $(\mathrm{P}<0.05-0.001)$

According the above data, the level of $\mathrm{T}$ lymphocytes and T-helper cells in patients is reduced ( $\mathrm{P}<0.05)$, with the most pronounced in women with CIN III ( $\mathrm{P}<0.01)$. At the same time, there was an increase in the level of $\mathrm{T}$-suppressors with the maximum value in women of the 3 rd group $(\mathrm{P}<0.001)$. The immunoregulation index was biased towards an increase in suppressor activity $(\mathrm{P}<0.001)$. Analysis of the data on the study of killer activity showed that with CINI, a significant increase in the level of CD16 + cells was observed, and with the development of neoplasia, suppression of killer activity was observed. The data obtained indicate the activation of the T-cell cytotoxic component in the examined patients.

The mean CD20 + value in patients with CIN I was elevated. While with CIN II and III, their decrease was observed $(\mathrm{P}<0.05)$. Studies have shown that the content of T-lymphocytes expressing the CD25+ molecule was within the normal range in $22.5 \%$ of women with CIN I. In CIN I, a significant increase was observed, while in women with CIN II and III, there was a decrease in blood levels of CD95 + cells (P> $0.05)$. Decreased serum $\operatorname{IgA}$ was detected in $86.9 \%$ of women with CIN II-III and in $1(10 \%)$ women of the CIN I group ( $\mathrm{P}<0.01)$. A low level of serum $\operatorname{IgA}$ creates an opportunity for persistence and reinfection of HPV (Table 2). Within the normal range, the concentration of serum IgM in women remained CIN I. However, their level tended to significantly increase in women with CIN II and III ( $\mathrm{P}<0.05)$.

THE STATE OF HUMORAL IMMUNITY OF WOMEN (MG /\%)

\begin{tabular}{|c|c|c|c|c|}
\hline Indicator & $\begin{array}{c}\text { Control } \\
\mathrm{n}=24\end{array}$ & $\begin{array}{c}\text { CIN I } \\
\mathrm{n}=45\end{array}$ & $\begin{array}{c}\text { CIN II } \\
\mathrm{n}=35\end{array}$ & $\begin{array}{c}\text { CIN III } \\
\mathrm{n}=31\end{array}$ \\
\hline Ig G & $1017 \pm 2,2$ & $1107 \pm 6,1$ & $1173 \pm 5,2^{*}$ & $1141 \pm 4,8^{*}$ \\
\hline Ig A & $197 \pm 1,0$ & $183 \pm 1,1^{*}$ & $408 \pm 4,3^{*}$ & $172 \pm 1,8^{\wedge}$ \\
\hline Ig M & $157 \pm 1,3$ & $168 \pm 1,9$ & $224 \pm 3,5^{*}$ & $206 \pm 2,2^{*}$ \\
\hline
\end{tabular}

Note: where * - P <0.05-0.001 the significance of differences compared with the control; where ${ }^{\wedge}-\mathrm{P}^{*}<0.05$ 0.001 significance of differences compared with women CIN I

Low values of serum $\operatorname{IgG}(1017 \pm 2.2 \mathrm{~g} / 1)$ were detected in $22.5 \%$ of women with CIN I and in $1(10 \%)$ women of the control group ( $\mathrm{P}<0.05)$. These data also indirectly indicate the activation of humoral immunity in women with CIN. In most patients with CIN, the humoral immunity was insufficient (hyporeactivity or increased production of key Ig - IgG depending on the degree of CIN), and the prevalence of serum IgM, which is an "early" antibody of lower affinity [14,19], may indicate a decreased the effectiveness of 
neutralizing viral antigens in the extracellular environment. Our data confirm once again that the imbalance of immunocompetent cells, depending on the degree of CIN, is determined by the violation of the control mechanisms of protection of the macroorganism [24]. In most women with CIN, violations of the $\mathrm{T}$-cell immune response are manifested by a decrease in the ability to activate $\mathrm{T}$ lymphocytes with their normal content.

We found a significant decrease in the ability of blood cells to respond with interferon products in response to the effects of inductors, which indicates the presence of a long period of hyporeactivity - a distinctive feature of severe chronic inflammatory process in most of the patients we examined. We found that the cytokine status of the majority of patients with CIN were violated more significantly than the indicators of cellular immunity. Thus, IFN- $\gamma$ was practically not detected in women with CIN II and III, while the frequency of INF- $\gamma$ detection was only $12 \%$. the level of proinflammatory cytokines in women with CIN was significantly higher than the control group. the level of tumor necrosis factor in women with CIN II was 2.5 times higher than the values of women in the control group $(\mathrm{P}<0.001)$, whereas in women with CIN III this value was increased more than 3 times ( $P$ $<0.001)$.

Studies have shown that with CIN II, the level of IL-2 increased by 1.8 times ( $\mathrm{P}<0.001)$, and in patients with a diagnosis of CIN III, this figure was increased 5.3 times. According to the literature, the participation of IL-2 is equally important both for the induction of specific T-killers and for the activation of nonspecific antitumor defense mechanisms [5,6].

Thus, one of the links in the pathogenesis of squamous intraepithelial damage is damage to the immune system of the mucous membrane of the cervix, which causes functional discoordination of cellular renewal and contributes to the development and progression of pre-tumor structural changes in the mucous membrane of the cervix.

\section{LIST OF USED LITERATURE}

1. Apolikhina, I.A. Papillomavirus infection of the genitals in women / I.A. Apolihina. M .: Izd. House GEOTAR-MED, 2002. - $111 \mathrm{p}$.

2. Autenshlyus, A.I. Evaluation of pro- and antiinflammatory factors of immunity in women with cancer and with dysplasia of the genital sphere / A.I. Autenshlyus, A.P. Lykov, A.N. Shkunov and others //

3. Kiselev V.I. Etiological role of human papillomavirus in development

4. cervical cancer: genetic and pathogenetic mechanisms / Kiselev VI, Kiselev OI // Cytokines and inflammation. - 2003. - V. 2, № 4. - P. 31-38.

5. Telesheva, L.F. Cytokine status of peripheral blood and cervical mucus in women with cervical neoplastic processes associated with human papillomavirus m / L.F. Telesheva, OS Abramovskikh, I.Yu. Orner // Vestn. Ural honey. Acad. science. - 2010. -№4 (32). - pp. 49-51.

6. Cytokine expression in squamous intraepithelial lesions of the uterine cervix: implications for the generation of local immunosupression / S.L. Giannini,

7. W. AlSaleh, H. Piron, N. Jacobs [et al.] // Clin. Exp. Immunol. - 1998. -

8. Vol.113,N2.-P.183-189.

9. Cytokines in cervicovaginal washing fluid from patients with cervical neoplasia / M.Y. Tjiong, N. van der Vange, J.S. ter Schegget, M.P. Burger [et al.] // Cytokine. -2001.Vol.21.-P.357-360.

10. Human papillomavirus vaccines: World Health Organization position paper. Weekly Epidemiological Record. - 2009. - Vol. 84. - P. 18-131.

11. Tyring S.K. Human papillomavirus infections: epidemiology, pathogenesis,

12. and host immune response / Tyring S.K. // J. Amer. Acad. Dermatol.- 2000. - Vol. 43. - P. 218-226

13. Leon-Maldonado L., Wentzell E., Brown B. et al. Perceptions and Experiences of Human Papillomavirus (HPV) Infection and Testing among Low-Income Mexican Women // PLoS One. 2016. Vol. 11, N 5. Article ID e0153367.

14. Bansal A., Singh M.P., Rai B. Human papillomavirus-associated cancers: A growing global problem// Int. J. Appl. Basic Med. Res. 2016. Vol. 6, N 2. P. 84-89.

15. Paesi S., Correa L., Tregnago M.C., et al. Human papillomavirus among women with atypical squamous cells of undetermined significance in southern Brazil // Int. J. Gynaecol. Obstet. 2015. Vol. 128, N 1. P. 23-26.

16. Wheeler C.M., Hunt W.C., Schiffman M. et al. Human papillomavirus genotypes and the cumulative 2-year risk of cervical precancer // J. Infect. Dis. 2006. Vol. 194. P. 1291-1299.

17. WHO Guidelines for Treatment of Cervical Intraepithelial Neoplasia 2-3 and Adenocarcinoma in situ Cryotherapy, Large Loop Excision of the Transformation Zone, and Cold Knife Conization. Geneva : World Health Organization, 2014. ISBN-13: 978-92-4-150677-9

18. Santesso N., Mustafa R.A., Wiercioch W. et al. Systematic reviews and meta-analyses of benefits and harms of cryotherapy, LEEP, and cold knife conization to treat cervical intraepithelial neoplasia // Int. J. Gynaecol. Obstet. 2016. Mar. Vol. 132, N 3. P. 266-271.

19. NHS Cervical Screening Programme Colposcopy and Programme Management NHSCSP. 3rd ed. March, 2016.

20. Paraskevaidis E., Arbyn M., Sotiriadis A. et al. The role of DNA testing in the follow-up period after treatment for CIN: a systematic review of the literature // Cancer Treat. Rev. 2004. Vol. 30. P. 205-211.

21. Kocken M., Helmerhorst T.J., Berkhof J. et al. Risk of recurrent high-grade cervical intraepithelial neoplasia after successful treatment: a long-term multicohort study // Lancet Oncol. 2011. Vol. 12. P. 441-450.

22. Ayres, A.R. Cervical HPV infection in Brazil: systematic review / A.R. Ayres, G. Azevedo e Silva // Rev. Saude Publica. 2010. - Vol. 44, № 5. - P. 963-974.

23. Brown D.R., Shew M.L., Qadadri B. et al. A longitudinal study of genital human papillomavirus infection in a cohort of closely followed adolescent women // J. Infect. Dis. 2005. Vol. 191. P. 182 